\title{
EFFICACY OF TOPICAL 1\% PIMECROLIMUS CREAM IN THE TREATMENT OF ATOPIC DERMATITIS
}

\author{
SULTANA A ${ }^{1}$, BEGUM A $^{2}$, BHUIYAN MSI ${ }^{3}$, ZAKARIA ASM $^{4}$, RABIN F ${ }^{5}$, FAKIR AY ${ }^{6}$, AHMED S $^{7}$
}

\begin{abstract}
:
Background: Topical steroids remain as the mainstay of treatment of Atopic dermatitis (AD), but associated with numerous adverse events. So, searching a non-steroidal alternative is very crucial for the management of atopic dermatitis.

Aims and objective: To evaluate the efficacy of $1 \%$ cream in atopic dermatitis.

Methods: This randomized parallel group study was conducted in the department of Dermatology and Venereology, Bangabandhu Sheikh Mujib Medical University (BSMMU), Dhaka. Patients of $A D$ of Group $A(n=20)$ patients were allowed to apply a thin film of Pimecrolimus $1 \%$ cream (Elidel) and Group $B(n=20)$ were advised to apply white Vaseline to the affected skin once daily for 4 weeks. Main out come was measured fortnightly with SCORAD and statistical analysis was done with SPSS-13.

Results: SCORAD at $1^{\text {st }}$ visit was $49.76 \pm 17.25$ in group $A$ and $55.25 \pm 13.94$ in group $B$ $(p=0.275)$, at $2^{\text {nd }}$ visit $27.39 \pm 11.16$ for group $A$ and $50.05 \pm 14.69(p=0.001)$ and at $3^{\text {rd }}$ visit $12.08 \pm 6.87$ for group $A$ and $46.70 \pm 14.80$ for group $B$. After completion of treatment mean $( \pm S D)$ of percent of $S C O R A D$ reduction was $76.70 \pm 8.10$ in group $A$ and only $16.88 \pm 8.70$ in group $B(p=0.001)$. According to physician's global assessment 9 (45.0\%) patients of Pimecrolimus group and 2 (10.0\%) were cleared or almost cleared. None of the patients experienced any adverse effects.

Conclusion: Twice daily application of $1 \%$ Pimecrolimus cream is effective and well tolerated in the treatment of atopic dermatitis.
\end{abstract}

Key words: Pimecrolimus, Tacrolimus, Calcinurine inhibitor, Atopic dermatitis, Eczema.

J Dhaka Med Coll. 2011; 20(2) : 188-192.

\section{Introduction:}

Atopic dermatitis (AD) is a common skin condition affecting up to $18 \%$ of children and $2 \%$ of adults ${ }^{1}$. It is an itchy, inflammatory skin condition with a predilection for the skin flexures and is characterized by poorly defined erythema with edema, vesicles, and weeping in the acute stage and skin thickening (lichenification) in the chronic stage ${ }^{1-2}$. It has a negative impact on the quality of life (QOL) of children and their Parents and poses a therapeutic challenge to dermatologists ${ }^{3}$. The disease accounts for $10 \%$ to $20 \%$ of all referrals to dermatologists and about $30 \%$ of dermatologic consultations in general practice $^{4}$. Usually the symptoms can be fairly well controlled by the judicious use of corticosteroids, also in children and topical corticosteroids have been the mainstay of treatment of $\mathrm{AD}$ for 40 years ${ }^{5}$. The local and systemic side effects of topical steroids are well recognized. Local effects include skin atrophy,

1. Dr. Abida Sultana, DDV, Assistant Professor, Dept. of Dermatology \& Venereology, Bangabandhu Sheikh Mujib Medical University (BSMMU), Dhaka, Bangladesh.

2. Dr. Afrina Begum, Assistant Professor, Dept. of Gynae \& Obst. Dhaka Medical College, Dhaka

3. Dr. Mohammed Saiful Islam Bhuiyan, MD, Assistant Professor, Dept. of Dermatology \& Venereology, Bangabandhu Sheikh Mujib Medical University (BSMMU), Dhaka, Bangladesh.

4. Dr. ASM Zakaria, MD, Professor, Dept. of Dermatology \& Venereology, Bangabandhu Sheikh Mujib Medical University (BSMMU), Dhaka, Bangladesh.

5. Dr. Farzana Rabin, M. Phil. Assistant Professor, Dept. of Psychiatry, Holy Family Red Crescent Medical College, Dhaka, Bangladesh.

6. Dr. Abu Yusuf Fakir, MS, Assistant Professor, Dept. of Otolaryngology, Dhaka Medical College, Dhaka, Bangladesh.

7. Dr. Shamim Ahmed, M. Phil, Assistant Professor, Dept. of Radiology and imaging, Dhaka Medical College, Dhaka, Bangladesh.

Correspondence : Dr. Abida Sultana, Assistant Professor, Dept. of Dermatology \& Venereology, Bangabandhu Sheikh Mujib Medical University (BSMMU), Dhaka, Bangladesh. 
striae, telangiectasias, hypopigmentation, rosacea, perioral dermatitis and acne. Systemic side effects include adrenal suppression, cataracts, glaucoma and growth retardation in children ${ }^{6}$.

Pimecrolimus is a calcineurin inhibitor, it inhibits T-cell activation and maturation by inhibiting the transcription factor NFAT (nuclear factor of activated $T$ cells) and thus the transcription and release of Th1 and Th2 cytokines ${ }^{7}$. To date, the safety and efficacy of tacrolimus ointment and pimecrolimus cream have been evaluated in more than 18000 patients with atopic dermatitis and found safe and effective 8,9 . It has very few adverse effects, most the most common adverse effects of Pimecrolimus is burning and stinging sensations ${ }^{10}$. The current study was conducted to see the efficacy and safety of topical Pimecrolimus in the treatment of atopic dermatitis.

\section{Methodology:}

In this randomized, parallel group study forty patients with atopic dermatitis of both sexes but otherwise in good general health, were included in the study and enrolled in to two treatment groups (group-A and group-B) of equal twenty patients. Group-A patients were treated with $1 \%$ pimecrolimus cream applied twice daily for four weeks and group-B patients were advised to apply white Vaseline to the affected skin twice daily for 4 weeks. SCORAD index system was assessed at baseline and patients were assessed fortnightly. All patients were asked to report immediately if any problem develops during the study period. Finally SCORAD index was calculated at the $4^{\text {th }}$ week. All information was collected in a pre designed data sheet and was recorded. Monitoring of adverse effects after 4 weeks was noted by patient's complications, query and physical examination. Data was analyzed by computer with the help of SPSS (Statistical package for social sciences) win 13 software package.

\section{Result}

Equal twenty patients with atopic dermatitis were enrolled into two groups (group-A, Pimecrolimus) and (group-B, Emollient), mean $( \pm \mathrm{SD})$ age of the patients were $8.34 \pm 2.27$ (range 2-12) years for group-A and $7.43 \pm 1.86$ (range 1-12) years for group-B. Total duration of disease (mean \pm SD) were $41.67 \pm 21.92$ months and $34.23 \pm 19.56$ months for group A and group B respectively. At entry level disease severity in terms of SCORAD was $49.76 \pm 17.25$ in group $A$ and $55.25 \pm 13.94$ in group $B(p=0.275)$, at $2^{\text {nd }}$ visit $27.39 \pm 11.16$ for group A and $50.05 \pm 14.69(\mathrm{p}=0.001)$ and at $3^{\text {rd }}$ visit SCORAD was $12.08 \pm 6.87$ for group A and $46.70 \pm 14.80$ for group B. After completion of treatment mean $( \pm \mathrm{SD})$ of percent of SCORAD reduction was $76.70 \pm 8.10$ in group A and only $16.88 \pm 8.70$ in group $B(p=0.001)$. According to physician's global assessment $9(45.0 \%)$ patients of Pimecrolimus group and $2(10.0 \%)$ were cleared or almost cleared. None of the patients experienced any adverse effects.

Table-I

Demographic, clinical and immunological characteristics of the study population

\begin{tabular}{llll}
\hline & & Group-A (Pimecrolimus) & Group-B (Emollient) \\
\hline Number of patients & 20 & 20 \\
Sex: (M/F) & $16 / 4$ & $16 / 4$ \\
Age (years): mean \pm SD (range) & $8.34 \pm 2.27(2-12)$ & $7.43 \pm 1.86(2-12)$ \\
Total duration of disease in months: & $41.67 \pm 21.92(1-96)$ & $34.23 \pm 19.56(1-88)$ \\
mean \pm SD (range) & & & \\
Percent body involved: & up to 25\% & $85 \%$ & $95 \%$ \\
& $26-50 \%$ & $15 \%$ & $5 \%$ \\
Personal history of & Allergic rhinitis & $11(555.0 \%)$ & $7(35.0 \% * 8$ \\
& Asthma & $5(25.0 \%)$ & $3(15.0 \%)^{* *}$ \\
Hanifin \& Rajka criteria fulfill & Yes & $12(60.0 \%)$ & $17(85.0 \%)$ \\
& No & $8(40.0 \%)$ & $3(15.0 \%)^{* * *}$ \\
Serum IgE level & $601.30 \pm 423.18$ & $658.30 \pm 211.84 \#$ & \\
\hline
\end{tabular}

${ }^{*}$ Chi-square test was done to measure the level of significance, $p=0.695$.

**Fisher's Exact test was done to measure the level of significance, $p=0.204$.

$* * *$ Chi-square test was done to measure the level of significance, $p=0.704$.

\# $t$ test was done to measure the level of significance, $p=0.593$. 
Table-II

Distribution of clinical features

\begin{tabular}{lcc}
\hline Dermatological examination & Frequency & Percent \\
\hline Flexural lichenification or linearity & 15 & 75.0 \\
Ichthyosis palmer hyperlinearity or keratosiss pilaris & 1 & 5.0 \\
Tendency toward cutaneous infection & 15 & 75.0 \\
Tendency toward nonspecific hand or foot eczema & 3 & 15.0 \\
Nipple eczema & 3 & 15.0 \\
Cheilitis & 7 & 35.0 \\
Recurrent conjunctivitis & 9 & 45.0 \\
Dannie-morgan infra orbital fold & 9 & 45.0 \\
Keratoconous & 5 & 25.0 \\
Orbital darkening & 2 & 10.0 \\
Facial pallor or facial erythema & 6 & 30.0 \\
Pityriasis alba & 10 & 50.0 \\
Anterior neck fold & 7 & 35.0 \\
Itch when sweating & 13 & 65.0 \\
Food intolerance & 4 & 20.0 \\
Course influenced environmental \& emotional factor & 5 & 25.0 \\
White dermatographism or delayed blanch & 0 & .0 \\
\hline
\end{tabular}

$* * \mathrm{p}=0.695$, Fisher's Exact test was done to measure the level of significance.

${ }^{*} \mathrm{p}=0.204,{ }^{*}$ Chi-square test was done to measure the level of significance.

Table-III

Distribution of SCORAD by groups

\begin{tabular}{lccc}
\hline SCORAD index & \multicolumn{2}{c}{ Group } & $\mathrm{p}$ \\
& Case (Group 1) & Control (Group 2) & value \\
\hline $1^{\text {st }}$ visit & $49.76 \pm 17.25$ & $55.25 \pm 13.94$ & 0.275 \\
$2^{\text {nd }}$ visit & $27.39 \pm 11.16$ & $50.05 \pm 14.69$ & 0.001 \\
$3^{\text {rd }}$ visit & $12.08 \pm 6.87$ & $46.70 \pm 14.80$ & 0.001 \\
Percent of reduction from & $76.70 \pm 8.10$ & $16.88 \pm 8.70$ & 0.001 \\
$1^{\text {st }}$ visit to 3 & & \\
\hline
\end{tabular}

*t test was done to measure the level of significance.

Data was shown as Mean $\pm \mathrm{SD}$.

Table-IV

Proportion of patients rated as clear or almost clear of disease based on the investigator's global assessment in 6-week vehicle-controlled studies with Pimecrolimus 1\% cream

\begin{tabular}{lcc}
\hline Physician's global assessment & Group-A (Pimecrolimus) & Group-B (Emollient) \\
\hline Clear or almost clear & $9(45.0 \%)$ & $2(10.0 \%)$ \\
\hline
\end{tabular}




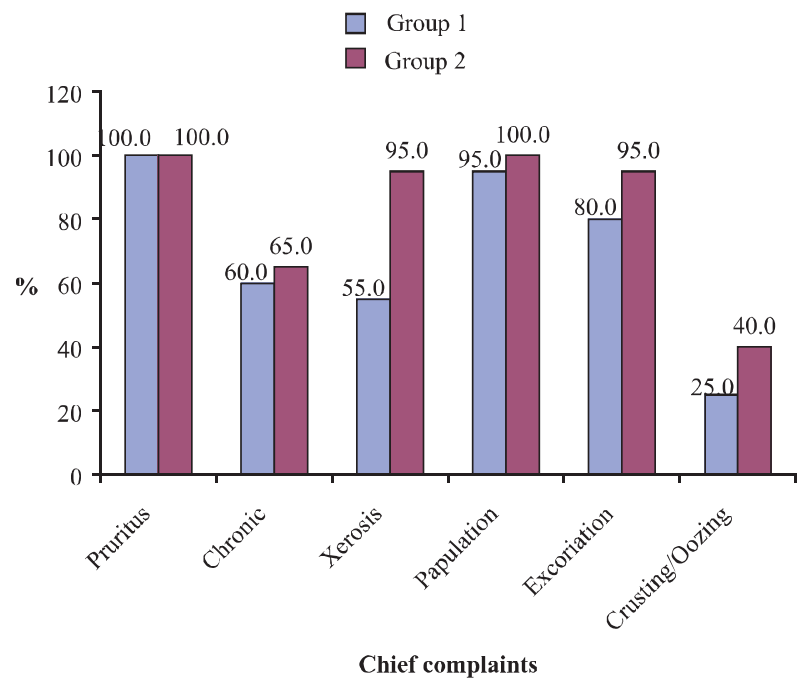

Fig.-1: Bar diagram of complains

\section{Discussion:}

Atopic dermatitis (AD) is a common inflammatory skin disease, causing significant physical, psychological and social distress ${ }^{11}$. Topical corticosteroids are the mainstay of treatment of atopic dermatitis but it has some potential adverse effects. The risk of steroidal side-effects is greater with longterm treatment and the use of potent corticosteroids ${ }^{12}$. For these reasons, corticosteroids are not recommended for longterm therapy, and potent preparations should not be used on the face, neck and intertriginous areas. Additionally, perceived concerns can adversely affect treatment by reducing patient compliance ${ }^{12}$. In a recent outpatient study, over $70 \%$ of patients were worried about using topical corticosteroids, and $24 \%$ were non-compliant because of these fears ${ }^{13}$. Therefore, there is currently a need for a potent, safe, nonsteroidal, topical treatment for atopic dermatitis. Tacrolimus ointment, formulated for the treatment of atopic dermatitis, is the first in a class of non-steroidal topical immunomodulators and it was approved by the US-FDA in December 2000 for the treatment of atopic dermatitis in patients above 2 yrs of age. Although large multicentric studies in adults and children have confirmed the efficacy of the drug in the treatment of atopic dermatitis $_{13-16 \text {, }}$ few studies have conducted to see the efficacy of Pimecrolimus in atopic dermatitis. The current study was carried out to see the efficacy of topical 1\% Pimecrolimus in the treatment of atopic dermatitis. It was a randomized parallel group study and conducted over forty patients of atopic dermatitis and all patients completed the treatment.

$\mathrm{AD}$ is a disease that primarily affects children, population particularly vulnerable to the systemic effects of several topical medications currently used to treat AD. Mean $( \pm \mathrm{SD})$ age of the patients were $8.34 \pm 2.27$ years with a range of 2 to 12 years in group-A and $7.43 \pm 1.86$ years with a range 1 to 12 years for group-B. In similar type two 6-week randomized, doubleblind, vehicle-controlled studies with Pimecrolimus comprised with children 1-17 years of age and one study with infants aged 3-23 months ${ }^{17-18}$. Pimecrolimus is an ascomycin derivative that is chemically unrelated to corticosteroids ${ }^{19}$.

At base line SCORAD index in case group was $49.76 \pm 17.25$ and in control group was $55.25 \pm$ 13.94 ( $>0.05)$. So, at baseline both treatment groups were statistically indifferent clinically and immunologically (IgE) (Table 1). In group A, after treatment with topical $1 \%$ pimecrolimus cream disease severity was reduced to $27.39 \pm 11.16$ and $12.08 \pm 6.87$ at $2^{\text {nd }}$ and $3^{\text {rd }}$ visit and in group B, it was reduced to $50.05 \pm 14.69$ and $46.70 \pm 14.80$. The mean $( \pm \mathrm{SD})$ of percent reduction of disease in group $A$ and $B$ was $76.70 \pm 8.10$ and $16.88 \pm 8.70$ respectively ( $\mathrm{p}=0.001)$. According to physician's global assessment 9 (45.0\%) patients of Pimecrolimus group and $2(10.0 \%)$ were cleared or almost cleared, whereas in previous studies by week 6 , treatment success was observed in $34.8 \%$ of children in the pimecrolimus group, compared with $18.4 \%$ of children in the vehicle group $^{20}$ and in another study in $54.5 \%$ of infants treated with pimecrolimus vs. $23.8 \%$ of vehicle-treated infants ${ }^{21}$. So, Pimecrolimus makes significant improvement of disease and it is marked better than only emollient. In other previous studies, 1\% Pimecrolimus cream was found effective and well tolerated when used on the face and neck, which are difficult areas to treat because of the risk of local adverse events associated with the use 
of higher potent topical corticosteroids ${ }^{22-23}$. In the present study, no instance of atrophy were reported in any patient receiving pimecrolimus cream, which is consistent with a similar type previous study, where the atrophogenic potent ial of pimecrolimus cream $1 \%$ was assessed in more detail in healthy volunteers; after 4 weeks of treatment, no evidence of skin atrophy was found in areas treated with $1 \%$ pimecrolimus cream $^{23}$. Eichenfield et $\mathrm{al}^{22}$ found that the efficacy and safety is sustainable on long term (26 weeks) use of $1 \%$ Pimecrolimus cream, but the current study was a short term study. So, we can conclude that $1 \%$ Pimecrolimus is safe and effective treatment modality for atopic dermatitis and we recommend to conduct further large scale prospective clinical trial to see the efficacy of $1 \%$ pimecrolimus crème in the treatment of atopic dermatitis.

\section{References:}

1. Ellis CN, Drake LA, Prendergast MM, Abramovits $\mathrm{W}$, Boguniewicz $\mathrm{M}$ et al. Cost of atopic dermatitis and eczema in the United States. J Am Acad Dermatol 2002;46:361-70.

2. Aoki T, Fukuzumi T, Adachi J, Endo K, Kojima M. Re-evaluation of skin lesion distribution in atopic dermatitis: analysis of cases 0 to 9 years of age. Acta Derm Venereol Suppl (Stockh) 1992;176:19-23.

3. Hanifin JM, Cooper KD, Ho VC, Kang S, Krafchik $\mathrm{BR}$, et al. Guideline of care for atopic dermatitis: developed in accordance with the American Academy of Dermatology (AAD)/American Academy of Dermatology Association "administrative regulations for evidence-based clinical practice guideline." J Am Acad Dermatol 2004;50:391-404.

4. Emerson RM, Williams HC, Allen BR. What is the cost of atopic dermatitis in preschool children? Br J Dermatol 2001; 144(3): 514-522.

5. Caproni M, Torchia D, Antiga E, Terranova M, Volpi W, et al. The comparative effects of tacrolimus and hydrocortisone in adult atopic dermatitis: an immunohistochemical study. $\mathrm{Br} \mathrm{J}$ Dermatol 2007;156:312-9.

6. Correlae CE, Walker C, Murphy L and Craij TJ, Atopic Dermatitis: A Review of Diagnosis and Treatment. Am Fam Physician 1999;60:1191-210.

7. Hanifin JM, Paller AS, Eichenfield L, Clark RA, Korman N, Weinstein G, et al. US Tacrolimus Ointment Study Group. Efficacy and safety of tacrolimus ointment treatment for up to 4 years in patients with atopic dermatitis. J Am Acad Dermatol 2005; 53 (Suppl 2): S186- 194.

8. Rico MJ, Lawrence I. Tacrolimus ointment for the treatment of atopic dermatitis: clinical and pharmacologic effects. Allergy Asthma Proc 2002; 23: $191-7$.

9. Eichenfield LF, Beck L. Elidel (pimecrolimus) cream $1 \%$. a non-steroidal topical agent for the treatment of atopic dermatitis. J Allergy Clin Immunol 2003; 111: 1153-68.

10. Tjioe M, Gerritsen MJ, Juhlin L, et al. Treatment of vitiligo vulgaris with narrow band UVB (311 $\mathrm{nm}$ ) for one year and the effect of addition of folic acid and vitamin B12. Acta Derm Venereol 2002; 82 (5): 369-72.

11. Williams HC. Epidemiology of atopic dermatitis. Clin Exp Dermatol 2000; 25(7): 522-529.

12. Alomar A, Berth-Jones J, Gianetti A, Reitamo S, Ruzicka T, et al. The role of topical calcineurin inhibitors in atopic dermatitis: British Journal of Dermatology 2004; 151 (Suppl. 70): 3-27.

13. Hanifin JM. Tacrolimus ointment for the treatment of atopic dermatitis in adult patients. Part I: Efficacy. J Am Acad Dermatol 2001;44:528-38.

14. Paller A. A 12 week study of Tacrolimus ointment for the trestment of atopic dermatitis in paediatric patients J Am Acad of Dermatol 2001;44:547-57.

15. Ruzicka T. A short term trial of tacrolimus ointment for atopic dermatitis. European Tacrolimus multicentric atopic dermatitis study group. New Eng J Med 1997;377:816-21.

16. Boguniewicz M. A randomized vehicle controlled trial of Tacrolimus ointment for the treatment of atopic dermatitis in children. J Allergy Clin Immunol 1998;102:637-44.

17. Charman CR, Morris AD, Williams HC. Topical corticosteroid phobia in patients with atopic eczema. Br J Dermatol 2000; 142:931-6.

18. Rudikoff D, Lebwohl D. Atopic dermatitis. Lancet 1998;351: 1715-21.

19. Woodmansee D, Christiansen S. Atopic dermatitis. Pediatr Ann 1998;27:710-6.

20. Eichenfield LF, Lucky AW, Boguniewicz M. Safety and efficacy of pimecrolimus (ASM 981) cream 1\% in the treatment of mild and moderate atopic dermatitis in children and adoles-cents. J Am Acad Dermatol 2002; 46: 495-504.

21. Ho VC, Gupta A, Kaufmann R et al. Safety and efficacy of non-steroid pimecrolimus cream $1 \%$ in the treatment of atopic der-matitis in infants. J Pediatr 2003; 142: 155-62.

22. Eichenfield LE, Lucky AW, Boguniewicz M, Barbier N and Cherill R. Sustained Efficacy and Safety of Pimecrolimus Cream 1\% when Used Long-term (up to 26 Weeks) to Treat Children with Atopic Dermatitis. Pediatric Dermatology 2008; 25 (3): 301-307.

23. Queille-Roussel C, P aul C, D uteil L et al. The new topical ascomycin derivative SDZ ASM 981 does not induce skin atrophy when applied to normal skin for 4 weeks: a randomized, doubleblind controlled study. $\mathrm{Br} \mathrm{J}$ Dermatol 2001;144:507-513. 